WÜNSCH, Thomas, PATSCHOVSKY, Alexander, Das Reich und Polen. Parallelen, Interaktionen und Formen der Akkulturation im hohen und späten Mittelalter

\title{
Sylvain Gouguenheim
}

\section{(2) OpenEdition}

Édition électronique

URL : http://journals.openedition.org/ifha/858

DOI : $10.4000 /$ ifha.858

ISSN : 2198-8943

\section{Éditeur}

IFRA - Institut franco-allemand (sciences historiques et sociales)

\section{Référence électronique}

Sylvain Gouguenheim, « WÜNSCH, Thomas, PATSCHOVSKY, Alexander, Das Reich und Polen. Parallelen, Interaktionen und Formen der Akkulturation im hohen und späten Mittelalter », Revue de l'IFHA [En ligne], Date de recension, mis en ligne le 01 janvier 2005, consulté le 22 septembre 2020. URL : http:// journals.openedition.org/ifha/858 ; DOI : https://doi.org/10.4000/ifha.858

Ce document a été généré automatiquement le 22 septembre 2020.

(CIFHA 


\title{
WÜNSCH, Thomas, PATSCHOVSKY,
} Alexander, Das Reich und Polen. Parallelen, Interaktionen und Formen der Akkulturation im hohen und späten Mittelalter

\author{
Sylvain Gouguenheim
}

1 Le thème des échanges culturels comme celui des diverses formes d'acculturation est à la mode. Il est particulièrement intéressant à étudier dans le cas de pays ou de peuples que l'Histoire a souvent opposés, dans le cadre de conflits réels que les historiographies nationalistes ont souvent exacerbés. L'opposition Allemagne/ Pologne fait partie de ces conflits européens que l'on suppose avoir été permanents. Néanmoins les échanges entre les mondes allemand ou impérial et polonais n'ont pas systématiquement pris la forme de conflits armés : des marchands sont passés d'un univers à l'autre, des monastères ou des intellectuels ont procédé à des échanges, des modes artistiques ont franchi les frontières, des colons sont venus dans des terres étrangères, se fondre avec la population locale. Une Germania slavica s'est peu à peu formée, tandis que la Pologne s'intégrait de plus en plus à la chrétienté latine.

2 Le grand mérite de l'ouvrage coordonné par T.W. et A.P. est d'aborder plusieurs thèmes dans un long intervalle chronologique, de l'an mil au début du XVIe s : celui, trop négligé dans les études médiévales, des relations internationales ; celui de l'administration territoriale et de la manière dont elle assure la domination des Princes ; celui des migrations de populations (paysannes ou étudiantes) ; celui des échanges intellectuels et artistiques. Enfin sont proposées des interrogations sur la conscience ethnique ou nationale.

3 A. LABUDA traite des relations artistiques, notamment à travers les exemples des liens entre Cracovie et le Sud de l'Allemagne. Ch. LÜBKE s'intéresse au thème des relations internationales en prenant l'exemple des volontés hégémoniques dirigées vers la terre 
de Halic-Volyn jusqu'en 1387. J. HOENSCH montre quelle fut l'importance de la Pologne dans le concert des forces politiques est-européennes des XIIIe-XVe s. W. IRGANG dresse une comparaison instructive autour du thème de la Libertas ecclesie et des formes qu'elle a pris dans l'Empire et en Pologne.

L'administration des territoires a pris des aspects différents, qu'analyse $\mathrm{K}$. MODZELEWSKI, permettant de mieux comprendre comment les divisions des circonscriptions permettaient aux souverains ou aux Princes de dominer leurs terres (examen des notions d'Opole, de centena et de pagus). C'est également au fonctionnement des hiérarchies administratives que s'intéresse J. KURTYKA, en comparant les différents offices des cours polonaises et est-européennes. Un seul article aborde le domaine de l'Ordre teutonique : A. RADZMINSKI y donne un tableau très précis de l'évolution de l'Église dans la Prusse teutonique jusqu'à la sécularisation de 1525. Les relations avec la hiérarchie de l'Ordre ne furent pas toujours aisées, dans un pays où les évêques disposaient d'un tiers du territoire et où celui d'Ermland parvint à conserver une autonomie tout au long de la période.

5 Si les migrations paysannes issues d'Allemagne vers les pays slaves sont bien connues, celles des chevaliers (milites, Ritter) le sont moins. T. JUREK met en valeur leur importance au sein de l'Ostbewegung, comme l'un des éléments de l'acculturation germano-slave. Ce phénomène d'acculturation s'observe aussi à travers la culture de cour, étudiée dans le cas de la Pologne par W. IWANCZAK.

6 Tout aussi intéressantes s'avèrent les communications de K. OZOG sur le rôle des intellectuels au service de l'État en Pologne. Le conflit militaire et diplomatique entre la Pologne et l'Ordre teutonique a mis en valeur de fortes personnalités comme Johannes Falkenberg ou Paul Wladimir participant au concile de Constance.

7 L'intégration de la Pologne à l'univers intellectuel européen est minutieusement analysée par M. MARKOWSKI, qui présente notamment les manuscrits philosophiques et universitaires conservés en Pologne. On voit à quel point l'époque de Casimir le Grand, puis celle de Wladyslas Jagiellon a correspondu à une Blütezeit de la culture polonaise. De nombreux Polonais étudient en Allemagne (Erfurt) et il existe une communauté européenne des lettrés, en dépit de certaines oppositions nationales. La culture juridique ou scolastique est la même, comme le révèle l'identité des arguments déployés lors des conflits entre États.

8 Le monde monastique silésien (étudié par M. DERWICH) a constitué un trait d'union entre les cultures allemande et polonaise, au sein d'un mouvement plus vaste de communauté de pratiques cultuelles entre la Pologne et l'Empire que présente Th. WÜNSCH.

9 Enfin le thème de la formation de groupes ethniques fait l'objet des communications de A. JANECZEK et P. GORECKI. Les phénomènes d'assimilation, de résistance et de conscience de groupes sont réels mais ne doivent pas être systématisés : pour beaucoup de contemporains, les différences ethniques et linguistiques ne constituèrent pas des frontières impénétrables.

Au total, l'ensemble des contributions illustre le thème central de la dynamique des contacts et des interactions culturelles, qui montre que les identités politiques, tout en étant cohérentes, étaient parcourues de mouvements divers. L'acculturation a accompagné le processus de territorialisation des pouvoirs, et l'Ostbewegung n'est pas nécessairement synonyme de colonisation. 
11 Une conclusion dense d'A.P. résume les apports essentiels des contributeurs et propose de nouvelles pistes de recherche autour de ce " laboratoire » centre- et est-européen. Ce riche ouvrage invite à de nouveaux travaux, entre autres à partir des concepts de « zones hégémoniques » et de régions de contacts (Silésie, terre de Halic), tout en respectant un univers mental médiéval moins nationaliste qu'on ne l'a longtemps cru. Il s'inscrit dans un processus de définition de l'identité européenne, utile à notre époque où l'on parle souvent de l'Europe sans vouloir lui donner de frontières ni d'héritage précis.

12 Sylvain GOUGUENHEIM (École Normale Supérieure

13 Lettres et Sciences Humaines, Lyon) 